\title{
Evolução, natureza e fundamento do direito de propriedade.
}

\author{
Antônio Chaves \\ Catedrático de Direito Civll da Faculdade de \\ Direito da USP.
}

Afinal das contas, constituirá mesmo a propriedade individual um furto? Será manifestamente atentatória aos direitos do homem, precisa ser abolida, como querem alguns, ou, ao contrário, é uma instituição vivificadora, fundamental, ligada à prosperidade dos individuos, das nações, da própria humanidade, um como que complemento da personalidade. como sustentam outros?

Eis ai, pode-se dizer, o problema dos problemas do Direito das Coisas, pois sem uma colocação exata dos seus têrmos, sem uma compreensão adequada de como deve ser encarado, não conseguiremos apanhar os fios da meada que hão de nos conduzir a uma visão certa, não estritamente civilística, mas até mesmo política e social, de todos os demais institutos complementares, de sua natureza, de seus fundamentos, de suas finalidades.

Não resta dúvida que a concepção romana, e, mais ainda, a concepção feudal do direito de propriedade são coisas de museu, cuja re-exumação, em pormenor, pouco interêsse apresenta.

* Aula inaugural proferida na sessão solene de abertura dos cursos jurídicos, da Faculdade de Direito da USP, no dia 2 de março de 1970 . 
Mas não é despiciendo uma evocação, ao menos sumária, de evolução das idéias, que nos mostrará as balisas do passado, facilitará vislumbrar os possíveis desenvolvimentos futuros, e aplanará as tarefas da sua construção dogmática.

Não vamos entrar na discussão da procedência da doutrina já qualificada como "pura fantasia" de acôrdo com a qual a propriedade teria sido comunitária nos primórdios da civilização, ou se - como parece mais congruente com os instintos do homem, - o direito de propriedade privada exclusiva é inato, estando perfeitamente caracterizado desde os mais recuados tempos.

O testemunho dos povos pré-históricos e dos selvagens do nosso tempo nenhuma contribuição oferece, invocado como é tanto para a demonstração de que a propriedade, nas origens, era coletiva. como para a comprovação da tese oposta.

É com Roma que começa, como em tantos outros setores, o interêsse jurídico da matéria.

E verdade que, nos primeiros tempos, a propriedade individual quasi que desaparecia, diante do poder do "pater familias", sob cujo império formava-se uma verdadeira comunidade familial, que não era limitada apenas aos vinculados pelos laços do sangue ou do parentesco afim.

Isso porém constitui a demonstração da existência de um excessivo poder concentrado nas mãos do pater, e que não tardaria a abrandar, e não de um comunismo, mesmo parcial e conscientemente aceito.

Sem embargo da ausência de qualquer definição legislativa de propriedade, sem embargo sequer de só ao tempo de Justiniano ter-se firmado a compreensão de sua função econômica e social, tinham os romanos uma noção precisa do instituto e das suas notas características: senhoria absoluta, exclusiva e perpétua, alcançando tudo o que 
estivesse acima e tudo o que estivesse abaixo do solo, senhoria essa que era limitada às coisas corpóreas.

Não tardou porém que, aos poucos fôssem esmaecendo os caractéres a princípio claramente demarcados. Desaparece o caminho que contornava inteiramente a propriedade, isolando-a das demais, não se repetem as cerimônias sagradas de fixação das divisas, surgem as primeiras limitações, constituídas pelas servidões, alvitra-se um regime diferente para disciplinar a aquisição do tesouro e dos minérios, os impostos abrangem um número cada vez maior de imóveis.

Crescendo lentamente as restrições à propriedade, desponta já na época feudal, o conceito do relacionamento das limitações não ditadas ao acaso pelo arbítrio do detentor do poder público, mas voltadas para uma projeção publicística do poder.

São expressões de Caio Mário da Silva Pereira que assinala o fenômeno da dissociação da autoridade, criando células autocráticas, representadas pelo senhor, em tôrno do qual gravitam os que lhe devem vassalagem, rendemlhe homenagem, prestam-lhe serviços de guerra e de paz.

Em troca de segurança e de proteção, juravam servir o senhor e transferiam-lhe suas terras, limitando-se à sua fruição, entretecendo-se aos poucos uma rêde de auxílios e de alianças, a começar pelo rei, abrangendo todos os condes, barões e senhores feudais, até alcançar o mais humilde dos servidores da gleba.

“A propriedade imóvel é objeto de subordinação diferente e variada a uns e a outros, mas é também o símbolo do poder de comando. Dentro de sua terra, o nobre é soberano. Cobra tributos. Exige obediência. Distribui justiça. Mas não existindo senhor sem terra, a propriedade, que fôra outrora um vínculo místico de apoderamento, torna-se um laço político." 
'Temos aí, bem assinalada, a primeira manifestação do caráter político que haveria de marcar a coloração da propriedade no correr dos tempos.

Aos poucos vai se aprofundando a cisão entre o dominio eminente, pertencente ao soberano, o domínio útil do senhor feudal, e a fruição daquele que valoriza e enobrece a terra pelo seu trabalho, devendo, todavia, para tanto. pagar o tributo de vassalagem.

Eliminar essa superposição de conceitos, unificando a propriedade, constitue um dos méritos da revolução francesa.

Mas a tentativa de igualar os homens apenas redundou em que o predomínio, que outrora pertencia à aristocracia. foi sendo substituído pelo daqueles que detinham a propriedade, passando o homem a valer não pelos seus títulos de nobreza, mas pelo cabedal de que dispunha.

Dentro dessa concepção não é de admirar que o art. 554 do Código Civil francês, que tanta influência havia de exercer nas demais legislações, proclamasse que "A propriedade é o direito de gozar e de dispôr das coisas da maneira mais absoluta, desde que dela não se faça uso proibido pelas leis ou pelos regulamentos."

Mas o liberalismo econômico e o liberalismo político não deram os resultados esperados.

Aquêle, levando à concentração dos capitais nas mãos de alguns, graças ao avanço tecnológico e ao despreparo no trato dos problemas econômicos, aumentou de maneira intolerável a exploração do homem pelo homem.

Este é solapado pelas doutrinas socialistas, cuja propaganda condena a concentração de riquezas e profliga a iniqua distribuição dos bens, influenciando as massas, cada vez mais alfabetizadas, informadas e esclarecidas.

É dessa época a doutrinação de Engels e de Marx. desembocando na vitória da revolução de 1917 e confirmando, de certo modo, os vaticínios de LÉon Dugurt, que 
nas célebres conferências proferidas em 1902, em Buenos Aires, já havia sustentado que a propriedade deixaria de ser um direito subjetivo para converter-se numa função social dos possuidores da riqueza.

Na mesma ordem de idéias, Josserand incluíu no rol dos direitos abusivamente exercidos o direito de propriedade. quando não conforme à sua finalidade social.

\section{Epoca moderna. Direito comparado.}

Ao caráter político da propriedade, outro se acresce, na época moderna: o de natureza social, apenas entrevisto pela revolução francesa, que, se marcou um progresso. suprimindo grande número de ònus, de encargos e de limitações, fê-lo num sentido excessivamente individualista.

A igualdade política revelou-se ilusória, tão longe estava de resolver as questões decorrentes da desigualdade econômica.

Que interessa ao chefe de família o direito de escolher o Presidente da República, quando é incapaz de solucionar o problema da panela de comida para si e para a sua familia?

Generaliza-se o reconhecimento da importância muito maior da função social desempenhada por uma adequada regulamentação da propriedade, e mesmo nos países mais aferrados à tradição as idéias igualitárias também no campo cconômico não deixam de exercer influência marcante.

Expressou-o bem René Savatier, Les Métamorphoses économiques et sociales du Droit Civil d'aujourd'hui, 1948. p. 142 :

"Esta mistica do "caráter inviolável e sagrado da propriedade" não corresponde mais aos fatos. De um lado, na nossa sociedade, o proprietário. 
longe de ser um senhor soberano de seu bem, aparece como encarregado de um serviço social, de que êste bem torna-se instrumento. De outro lado, a humanidade tomou consciência de que a propriedade, que é sòmente matéria, não frutifica a não ser pelo trabalho do homem; a mão de obra humana reivindica pois a sua desfôrra contra a sujeição que lhe havia imposto a mística da propriedade."

Se não se "nacionalizam" os bens das companhias estrangeiras, se não se expropriam as fontes de produção em favor do Estado ou dos operários, como ocorre nos países socialistas, limitam-se por tôda parte as manifestações do poder outrora irrestrito, reduzem-se as possibilidades de transmissão integral de fortunas colossais aos herdeiros, através de taxações mais gravosas à proporção em que vai diminuindo o grau de parentesco, impõem-se limitações em favor da comunidade.

E sem embargo dessas vicissitudes, vencendo resistências, a propriedade segue seu curso. dando mostras de uma resistência e de um poder de adaptação admiráveis.

Evolução da propriedade no Direito Constitucional brasileiro.

Pouco menos de século e meio nos separam da Carta de Lei de 25-3-1824, que em seu art. 179, n. 22 garantia, "em tôda a sua plenitude", o direito de propriedade.

"Se o bem público legalmente verificado" - aditava - "exigir o uso e emprêgo da propriedade do cidadão, será êle prèviamente indenizado do valor dela. A lei marcará os casos em que terá lugar esta única exceção e dará as regras para se determinar a indenização."

Na mesma ordem de idéias o Código Civil ainda consigna na disposição do art. 544 que já está vazia de sentido, 
que a propriedade é o direito de gozar e dispor das coisas da maneira mais absoluta.

A Constituição de 1891, usando, sem subterfúgios, a palavra adequada, "desapropriação", que aquela pùdicamente havia evitado, mantém ainda, art. $72, \S 17$, "em tôda a sua plenitude" a propriedade, mas já ressalva a desapropriação por necessidade de utilidade pública e mediante indenização prévia, e dá início ao rol das restrições que, de constituição em constituição, outra coisa não faz senão aumentar progressivamente.

Nesta ficou consignado que: “a) As minas pertencem ao proprietário do solo salvo as limitações estabelecidas por lei, a bem da exploração das mesmas; b) as minas e jazidas minerais necessárias à segurança e defesa nacionais e terras onde existirem não podem ser transferidas a estrangeiros."

Coube à Constituição de 1934 colocar a propriedade dentro do esquema que caracteriza a época moderna, continuando a garantir, sim, o direito de propriedade, mas substituindo a referência individualista a "tôda a sua plenitude", à menção francamente coletivista da não possibilidade de seu exercício "contra o interêsse social ou coletivo".

A alusão foi completamente eliminada pela Carta de 1937, mas restabelecida, com amplitude maior, pela Constituição de 1946, condicionando francamente, no art. 147 seu uso ao bem estar social e autorizando ainda a lei, obedecidas as restrições constitucionais, a "promover a justa distribuição da propriedade com igual oportunidade para todos".

A Constituição de 1967 ressalvou, entre os princípios fundamentais da ordem econômica e social, cuja finalidade é a de realizar o desenvolvimento nacional e a justiça social, a "função social da propriedade", mantida “ipsis litteris" pela Constituição de 17-10-1969, art. 160. 
E o art. 153 deu ao princípio a seguinte redação no $\S 22$ :

"E assegurado o direito de propriedade, salvo o caso de desapropriação por necessidade ou utilidade pública, ou por interêsse social, mediante prévia e justa indenização em dinheiro, ressalvado o disposto no artigo 161, facultando-se ao expropriado aceitar o pagamento em títulos da dívida pública, com cláusula de exata correção monetária. Em caso de perigo público iminente, as autoridades competentes poderão usar da propriedade particular, assegurada ao proprietário indenização ulterior."

Pode-se chegar assim à conclusão de que está definitivamente insculpido em nosso direito, através de dispositivos da Lei Básica, o princípio irradiado da Constituição de Weimar, proclamando não apenas vantagens para o proprietário, mas denunciando as obrigações a que está sujeito e condicionando seu uso ao interêsse geral.

Já não pode mais ser qualificada, a rigor, como um direito subjetivo, é, antes, uma função social, pois o proprietário - na justa observação de Dugurr - deve "realizar certa tarefa, e não será socialmente protegido senão quando a cumpre, e na medida em que o faz."

\section{Natureza.}

Como, pois, considerar o direito de propriedade sob o ponto de vista do direito civil?

A doutrina começa por separar três conceitos diferentes: o filosófico, o econômico e o jurídico.

- Sob o primeiro aspecto, é a qualidade distintiva de uma coisa: 
- sob o segundo, é o aproveitamento por parte do homem das coisas da natureza;

- sob o terceiro, é o equivalente do domínio, correspondente ao mais pleno e ao mais típico dos direitos reais.

Limitando-nos ao exame sob o ponto de vista jurídico. começaremos, com Vancells. distinguindo o sentido amplo do restrito.

No primeiro aspecto, separam-se ainda três direções. conforme seja considerada:

a) como direito absoluto sôbre bens em geral, compreendendo não apenas as coisas corpóreas, como também as incorpóreas ou imateriais:

b) como um direito geral sôbre coisas corpóreas. com exclusão portanto das relações do homem com as coisas destituídas dêste caráter:

c) como um direito absoluto sôbre coisas corpóreas. no qual se compreendem não tôdas as relações da pesson com as coisas materiais, mas sòmente as que dão lugar ao direito pleno, ou domínio, e aos demais direitos reais.

"Ao lado dêste sentido amplo do direito de propriedade," - adita êsse autor - "no qual incluem alguns autores, dando-lhe uma excessiva extensão, os direitos sôbre bens imateriais, mal chamados propriedade intelectual e industrial, existe um sentido estrito e mais técnico, segundo o qual a propriedade é um direito pleno e geral sôbre coisas corpóreas, singulares, integras e específicas. Fsta é a concepção de WoLfF e de muitos tratadistas modernos, que identificam a propriedade com o direito de domínio, definindo-a aquêle como "o mais amplo direito de senhoria que pode-se ter sôbre uma coisa", e concebendo-a como um conjunto de faculdades que ordinàriamente pertencem ao proprietário, mas que em determinados casos podem faltar, por estarem atribuidas circunstancialmente a outras pessoas, sem que por isso o legítimo dono da coisa deixe de sê-lo, uma vez que será sempre o verda- 
deiro titular, embora privado temporàriamente de exercer uma ou algumas das faculdades do domínio, e conservará a possibilidade de poder voltar a exercer seu direito com tôda sua plenitude quando êste deixe de estar atribuído parcialmente a outras pessoas."

Separa Plutarco Marsá Vancells as definições analíticas, que pretendem explicar o direito de propriedade sob o ponto de vista puramente quantitativo, das sintéticas, que, com critério qualitativo, procuram dar um conceito unitário.

Dentre as primeiras transcreve a definição clássica, das antigas escolas: "Dominium est ius utendi atque abutendi re sua quatenus iuris ratio patitur"; e dentre as segundas, a curiosa conceituação das Partidas: "Señorio es poder que ome ha en su cosa de fazer della, e en ella lo que quisiere segund Dios, e segund fuero".

Uma das definições mais aplaudidas é a de Scialoja: "la proprietà è un rapporto di diritto privato, pel quale una cosa, come pertinenza di una persona, è completamente soggetta alla volontà di questa in tutto ciò che non sia vietato da diritto pubblico o dalla concorrenza dell'altrui diritto".

Critica-a, todavia, Cunha GonçAlves, qualificando-a como manifestamente insuficiente por lhe faltarem algumas das principais características do direito definido, implicando a frase "havida como pertencente" sòmente numa presunção ou aparência, ao passo que a propriedade é ou deve ser uma certeza.

Mais aprofundados os reparos de Bonfante destacando a excessiva preocupação de pôr em relêvo a antítese entre a propriedade - relação de direito privado - e a soberania, relação de direito público. Também não parece necessário enunciar o duplo perfil pelo qual à senhoria do proprietário sôbre a coisa corresponde uma relação de pertença desta àquele, uma vez que é próprio de qualquer 
direito ter ao mesmo tempo um aspecto positivo e correlativamente um aspecto negativo: potestas e subiectio.

Elıo Vitucci, que os reproduz, adita que a definição, pelo menos formalmente, equipara as proibições opostas ao proprietário no livre exercício do seu direito pelo direito público e as decorrentes da concorrência do direito alheio; aproximação inoportuna, quando se considera que os primeiros colocam limitações absolutas, diferentemente dos segundos, que a vontade do homem pode impor $\mathrm{e}$ eliminar.

Silencia por completo, finalmente, a respeito de um caráter essencial do domínio: a sua elasticidade, que faz com que readquira automàticamente a sua plenitude tão logo cessem as restrições impostas, seja qual fôr sua fonte e sua natureza.

Conclui adotando a definição de Ferrini: "é aquêle direito pelo qual uma coisa pertence a uma pessoa e fica sujeita a esta de modo, pelo menos virtualmente, universal."

De nossa parte preferimos, por ser menos genérica, a de Cunha Gonçalves: "direito de propriedade é aquêle que uma pessoa singular ou coletiva efetivamente exerce numa coisa certa e determinada, em regra perpètuamente, de modo normalmente absoluto, sempre exclusivo, e que tôdas as outras pessoas são obrigadas a respeitar."

\section{Caracteres.}

Dentro de uma relatividade que se acentua ora mais, ora menos, conforme seja considerado cada um dos elementos peculiares da propriedade, podemos dizer que se trata de um direito que, além da elasticidade já aludida, é unitário, absoluto, exclusivo, ilimitado, universal e perpétuo. 
É unitário, no sentido bem destacado por Fulvio Maror, de que não constitui uma série de faculdades que sejam autônomas com relação à propriedade, mas é uma senhoria geral, de que todos os possiveis poderes não constituem senão extrinsecações. Unitário também é o direito de propriedade como conceito.

É verdade que não faltam autores que pretendem ver não um só, mas uma pluralidade de direitos na propriedade.

Assim, Pugliatti, citado por Grovanni Silvio Coco, Crisi ed Evoluzione nel Diritto di Proprietà, Giuffrè, Milano, 1965, pág. 215: a expressão propriedade exprime demasiadas coisas para que se possa "manter a ilusão de que à unicidade do têrmo corresponda a real unidade de um sólido e compacto instituto."

E o próprio Coco chega à conclusão de que o instituto tem múltiplos componentes, ou, o que lhe parece substancialmente a mesma coisa, existem múltiplos institutos ou tipos de propriedade, ou até mesmo, múltiplas propriedades.

Mas a razão está com MaroI, que, contestando afirmações análogas de Vassalli, La Concezione della Proprietd. Roma, 1936, p. 103, obtempera que o fato do ordenamento jurídico supor limites diferentes, com base nas variadas exigências econômicas e sociais, não quer dizer absolutamente que êle reconheça diversos tipos de propriedade. uma vez que as diferenças dependem sòmente do diferente conteúdo econômico-social, e não de uma diversa estrutura jurídica.

É ainda um direito absoluto - porque, como se exprimia o catedrático desta Casa, Manoel Pagheco Prates, "o proprietário pode dispor de coisa como bem entender, salvo as modificações dêste poder estabelecidas ou exigidas pelo interêsse público, situação da coisa, ordem moral e vontade do proprietário." 
Adite-se, porém, que êsse conceito de absolutismo não exclui que para harmonizar os interêsses - tanto públicos como privados - encontre determinadas limitações que a lei indica expressamente.

E um direito exclusivo porquanto pode o proprietário excluir do objeto do seu direito, qualquer interferência de outrem. Isto sem embargo da circunstância anotada pelo mesmo tratadista, dêsse poder ser suscetível de modificacões, principalmente pela existência de um jus in re, quer êste seja instituído convencionalmente, quer exigido pela situaçâo da coisa, "pois é possível desmembrar certas parcelas da propriedade e erigi-las em direitos separados a favor de terceiros", sem que êstes desmembramentos privem o proprietário de dispor da coisa, que é da essência do direito de propriedade.

E ilimitado, não porque não tenha fronteiras, que existem, e, já vimos, vão gradativamente se acentuando, mas no sentido de que não é possível determinar, através de texios explícitos, o seu conteúdo. Apenas em sentido negativo é que a doutrina, e a própria legislação indicam o que é que o titular não pode fazer, daí se deduzindo. por via indireta, o conteúdo positivo do direito de propriedade.

f. um direito universal, pelo menos virtualmente, porquanto, se uma ou mais faculdades são subtraídas ao proprietário pelo concurso de outros direitos ou por ef eito de vínculos estabelecidos pela lei, - consigna o já citado Maror - a propriedade conserva a virtude intrínseca de voltar a expandir-se, de retornar à sua mais lata compreensão, de retomar a sua natura] universalidade, tão logo venham a se extinguir aquêles pesos ou vínculos, que a comprimem. É nesse sentido que se fala em elasticidade do direito de propriedade.

É, finalmente, de certa forma perpétuo, no sentido bem esclarecido, entre outros, por Cunha Gonçalves: "isto é. de duração ilimitada, embora seja transmissivel por con- 
trato, sucessão e outros meios legais. A transmissão é, até, um dos meios de tornar durável a propriedade, por tempo indefinido, visto que o adquirente é o sucessor do transmitente, a título singular ou universal; para aquêle passam todos os direitos que êste tinha na coisa transmitida. Por isso, a perpetuidade não significa que uma coisa deve pertencer, sempre, ao mesmo titular, o que seria impossivel, visto que os homens duram, em regra, menos do que as coisas de que são proprietários."

\section{O talvegue das concepções da propriedade.}

A essa tendência que se percebe nos países de civilização ocidental de "socializarem" de alguma forma a propriedade privada, quebrando e eliminando progressivamente rebarbas e arestas individualísticas capazes de ferir o interêsse coletivo, corresponde um dos fenômenos mais curiosos e característicos do nosso tempo: o de uma incipiente "individualização" da propriedade coletivista, que se nota nos países socialistas.

O regime do comunismo integral, heróico, ferrenho da propriedade, vai aos poucos se abrandando e humanizando, abrindo pequenas brechas para a manifestação pela menos em alguns bens, da propriedade individual.

No Capítulo relativo ao Direito Civil soviético que V. Serebrovski e R. Jálfina escreveram para Fundamentos del Derecho Sovietico, sob o patrocinio do Instituto do Estado e de Direito da Academia de Ciências da unss. Edições em Línguas Estrangeiras, Moscou, 1962, está consignado, a pág. 217:

"Os cidadãos da urss são sujeitos de direito da propriedade pessoal. De acôrdo com o disposto no artigo 10 da Constituição da urss, o direito dos cidadãos à propriedade pessoal está protegido pela lei. Cada cidadão da urss, independentemente do sexo, raça, nacionalidade, 
credo religioso e origem social pode possuir em direito de propriedade pessoal determinados bens indicados na Constituição da uRss."

E passam a esmiuçar os bens de que pode desfrutar pessoalmente cada lar kolkosiano: um pequeno terreno contiguo à casa, e, sôbre êsse terreno, como propriedade pessoal, uma propriedade agrícola auxiliar, morada, gado de produção, aves de quintal e pequenos conjuntos de animais de lavoura.

Alẻm dêstes, os membros do lar kolkosiano têm outros bens, que lhes pertencem pessoalmente e que não entram no patrimônio do lar kolkosiano.

"A Constituição da urss" — aditam textualmente "fixa entre os objetos de direito da propriedade pessoal dos cidadãos as entradas e poupanças decorrentes de seu trabalho, a casa de morada e a propriedade agrícola doméstica auxiliar, os objetos de uso doméstico, os objetos de uso, consumo e comodidade pessoal. Desta maneira. o grupo de objetos que podem pertencer aos cidadãos em direito de propriedade pessoal é consideràvelmente mais limitado do que os objetos de direito de propriedade do Estado e da cooperativa kolkosiana. As coisas destinadas a satisfazer as necessidades materiais e culturais dos cidadãos são objeto de direito de sua propriedade pessoal. Assim o determina a essência e o significado da propriedade pessoal na sociedade socialista."

Assinalam, entre outras considerações, que os cidadãos da urss gozam da faculdade de comprar ou construir para êles, em direito de propricdade pessoal, uma casa de moradia, de um ou dois andares, com um número de. quartos até cinco, dentro ou fora da cidade, contanto que a superfície total não exceda de $60 \mathrm{~m} 2$, prestando mesmo o Estado ajuda aos trabalhadores na construção individual de casas de moradia.

Nem se pode afirmar - convenhamos - qualquer contradição com o manifesto do Partido Comunista de 
1848, que propunha sim, a abolição da propriedade privada dos instrumentos de produção, consignando, porém, que "o traço distintivo do comunismo não é a abolição da propriedade em geral, mas sim a abolição da propriedade burguêsa."

Mas as concessões aos princípios individualistas são maiores das que transparecem dêsses textos.

Darcy Bessone de Oliveira Andrade, depois de lembrar que, com a nova politica econômica Lenine considerou, em 1921 que o interêsse social recomendava a revisão das drásticas soluções de 1918, assinala a similitude entre o art. 58 do Código Civil soviético de 1922, em cujos têrmos "o proprietário tem o direito de posse, uso e disposição de seus bens, dentro dos limites estabelecidos por lei", e o art. 524 do Código Civil pátrio, "A lei assegura ao propriefário o direito de usar, gozar e dispor de seus bens, e de reavê-los do poder de quem quer que injustamente os possua."

“Mesmo, porém, após o repúdio da N.E.P., não se excluiu a possibilidade da acumulação de riquesas, formando-se verdadeiras fortunas, constituidas por contas em bancos (com juros até $5 \%$ ), bonus do Tesouro, residências privadas, automóveis. móveis. vestuário, bibliotecas, etc., afastada, assim, a jdéia de igualitarismo, que não passaria de uma deformação do pensamento socialista através de "une doctrine sociale utopique bourgeoise" (RENÉ David e John N. Hazard - Le Droit Soviétique, t. II, pág. 25)."

Do confronto dos dois fenômenos não há como não concluir que diminui, pouco a pouco, a distância entre as duas concepcões, levando fatalmente um dia, senão a um ponto de equilíbrio, pelo menos a perceber que não se trata de uma distância tão grande.

Não há encostas, por mais largas e escarpadas, que não se encontram num talvegue: se existem córregos de 
água que as separam, se os planos são diferenciados, haverá sempre pontos de aproximação e de similitude!

\section{Conclusão.}

Voltando às perguntas iniciais: estamos diante de uma crise da propriedade?

Não falta quem, fazendo éco às diatribes que contra ela têm sido lançadas, responda afirmativamente.

Mas crise por quê, se nunca como agora é reconhecida e proclamada a sua utilidade, a tal ponto que é justamente em decorrência das suas indiscutiveis vantagens que não se permite mais fique adstrita ao âmbito limitado e egoistico do seu titular, mas se exige que se espraie em benefícios à tôda a coletividade?

Digamos antes evolução das funções da propriedade, de acôrdo com a finalidade social que todos reconhecem que ela desempenha.

Tálvez um dia haja coincidência em reconhecer que se trata mais de um diréito de ordem pública do que de interêsse particular, ou quem sabe se realize o vaticínio de Dugurr, segundo o qual virá a época em que a lei obrigue o proprietário a cultivar o seu campo, a manter as suas casas $\mathrm{cm}$ bom estado de conservação, a fazer produzir os seus capitais, não se contentando em impor limites, mas traçando verdadeiras obrigações ao proprietário, para satisfações de interêsses de ordem coletiva.

Mas à pergunta fundamental não há dúvida que a resposta é a de que a propriedade merece ser conservada.

Iustifica plenamente Cuvina Gonçalves a existência da propriedade individual pelos grandes serviços que tem prestado à humanidade, não só inspirando as primeiras idéias de justiça e de moral, pelo suum cuique tribuere, mas incutindo aos homens o desejo e a alegria do trabalho, 
para conquistarem a sua independência econômica ou a riqueza.

"Ela tem sido a fonte primacial do incremento de tôdas as riquezas, de tôdas as invenções e descobertas, de todos os progressos da indústria. do comércio, das artes, das ciências, e até da literatura, de tudo aquilo que a palavra "Civilização" resume. $\mathrm{O}$ egoísmo é o caráter mais geral e fundamental do homem. É inútil esperar que êste se afadigue espontâneamente por altruismo de desinterêsse, só para contribuir ao bem estar dos outros. Sem a propriedade, o homem não trabalharia senão o indispensável para o seu sustento pessoal. Se é possivel privar o indivíduo da propriedade da terra ou de certos imóveis, em proveito da coletividade, é absurdo privá-lo de tôda e qualquer propriedade."

"O que não se pode desconhecer, porém," - consigna por sua vez o saudoso Eddurdo Espínola, "Posse - Propriedade - Compropriedade ou Condomínio - Direitos Autorais", Conquista, Rio, 1956, p. 132 - "é que a vida social e as normas jurídicas que a regulam, em qualquer período da história dos povos civilizados demonstram o reconhecimento da propriedade individual em tôdas as relações da convivência humana, de modo direto ou indireto: é para adquirí-la que se esforça o trabalho do homem, nos vários ramos da produção; todo o direito das obrigações pressupõe a propriedade privada, quer nas transferências, quer nos contratos de outra espécie; nela se baseia a matéria da sucessão hereditária; a ela se aplica o direito de família, quanto ao regime de bens, à obrigação alimentícia."

Ora, se considerarmos o problema com isenção de ânimo, havemos de convir em que não existe qualquer crise de propriedade, e sim que ela passa por mais uma 
das tantas fases de acentuada evolução, acompanhando o dinamismo da época em que vivemos.

Mas a malcabilidade de que tem dado tantas provas, êsse poder admirável de adaptação a tôdas as contingências, a tôdas as pressões, a tôdas as políticas, o extraordinário poder de sobrevivência de que é dotada, há de permitir-lhe enfrentar vicissitudes, satisfazer exigências, cumprir sacrifícios.

Demonstrou Grovanni Silvio Coco que a propriedade privada já não pode ser considerada uma entidade ontológica, uma essência com atributos próprios, que se devam conhecer e sistematizar, mas um conceito, com o qual se justifica de modo jurídico a apropriação privada dos bens e se exprime unitàriamente a sua disciplina.

“... Cumpre superar a colocação clássica do direito pleno e exclusivo e dos limites e tornar patente que hoje se vão delineando e consolidando novas perspectivas jurídicas, em que o interêsse do proprietário não é o objeto central da proteção, mas um interêsse tutelado no quadro de um conjunto de interêsses com êle contrastantes, que insistem juntamente sôbre a coisa objeto de domínio e que o ordenamento reconhece e ampara além da barreira tradicionalmente colocada em defésa do proprietário."

ArNoldo Wald, na admirável prova escrita com que se sagrou vitorioso no preenchimento da Cadeira de Direito Civil da Faculdade de Direito da Universidade do Estado da Guanabara, também realça o esfôrço de adaptação do instituto, que lhe dá maior fôrça e maior utilidade, transformando a propriedade num instrumento adequado ao serviço do homem. do seu desenvolvimento e da sua integração na sociedade.

$\mathrm{E}$ adita: " $\mathrm{O}$ individualismo exacerbado fêz um pouco do homem o escravo da propriedade, considerada como fin e não como meio. A democratização da propriedade, que significa a sua proletarização e sua humanização, 
pretende inverter os dados do materialismo e fazer da propriedade um meio de liberação do homem e de sua completa realização.

"O verdadeiro individualismo é o que não sacrifica a sociedade ao interêsse da pessoa ou do grupo, mas faz da sociedade e dos bens meios para atender ao pleno desenvolvimento da pessoa humana, no plano material e espiritual. A evolução da propriedade e as suas novas dimensões são elementos que apresentam uma importante contribuição para alcançar tal desideratum que é uma imposição para a salvaguarda da nossa cultura ocidental e cristã, em cujo espírito tem vivido e há de viver sempre o nosso direito."

Nada de crise, portanto, mas, muito ao contrário, evolução. Evolução auspiciosa, que irá nos levar ao ponto de equilibrio.

Através de uma atenuação das desigualdades, que apenas se inicia, pela reforma agrária, pela participação dos trabalhadores nos lucros das emprêsas, pela popularização dos capitais das grandes sociedades, alcançaremos, sem dúvida, uma adaptação da propriedade privada a fins mais humanos, mais dignos, mais construtivos, daqueles que resultariam de um vão e estéril individualismo.

\section{Bibliografia.}

ANDrade, Darcy Bessone de Oliveira, A Propriedade, in "Jurídica", n. 83, 1963, pgs, 456-471.

Coco, Giovanni Silvio, Crisì ed Evoluzione nel Diritto di Proprietà, Giuffrè, Milano, 1965, 247 págs.

Cunha Gonçalves, Luiz, Tratado de Direito Civil, $2 .^{a}$ ed., Limonad, S. Paulo, s/, v. XI, t. I, pgs. 175-246.

Espinola, Eduardo, Posse, Propriedade,Compropriedade ou Condominio, Direitos Autorais, Conquista, Rio, 1956, pgs. 127-133.

Maror, Fulvio, verb. Proprietá in "Dizionario Pratico del Diritto Privato", Vallardi, Milano, 1952, v. V, p. II, pgs. 693-704. 
VAncells, Plutarco Marsá, verb. Propriedad, in "Dicionario del Derecho Privado", Labor, Barcelona, 1961, t. II, pgs. 3 149-3 152.

VıtuccI, Elio - verb. Proprietá (Diritto Civile) in "Nuovo Digesto Italiano", Utet, Torino, 1939, v. X, pgs. 673-695.

WALD, Arnold - Novas Dimensões do Direito de Propriedade, in "Revista dos Tribunais", v. 376, 1967, pgs. 8-17 e Separata de “Jurídica", n. 95, 1966, pgs. 3-18. 